plasminogen activator in pancreatic adenocarcinoma is regulated by constitutively activated RelA. Oncogene, 1999. 18(32): p. 4554-63.

6. Shukla, S., et al., Nuclear factor-kappaB/p65 (Rel A) is constitutively activated in human prostate adenocarcinoma and correlates with disease progression. Neoplasia, 2004. 6(4): p. 390-400.

7. Xia, Y., S. Shen, and I.M. Verma, NF-kappaB, an active player in human cancers. Cancer Immunol Res, 2014. 2(9): p. 823-30.

8. Thompson, J.D., D.G. Higgins, and T.J. Gibson, CLUSTAL W: improving the sensitivity of progressive multiple sequence alignment through sequence weighting, position-specific gap penalties and weight matrix choice. Nucleic Acids Res, 1994. 22(22): p. 4673-80.

\title{
NGHIÊN CỨU VAI TRÒ CỦA CHỤP CộNG HƯỞNG TỪ TRONG CHẨN ĐOÁN RÒ HÂ̂U MÔN HÌNH MÓNG NGỰA TẠI BỆNH VIỆN VIÊTT ĐỨC
}

\author{
Bùi Sỹ Tuấn Anh ${ }^{1}$, Nguyễn Xuân Hùng ${ }^{2}$, Trịnh Hồng Sơn ${ }^{2}$
}

\section{TÓM TẮT}

Mục tiêu nghiên cứu: Xác định mức độ phù hợp giữa chụp cộng hưởng từ (CHT) hậu môn trực tràng và phấu thuật trong đánh giá lỗ trong và đường rò hậu môn hình móng ngựa. Đối tượng và phương pháp nghiên cứu: Những bệnh nhẩn được chẩn đoán rò hậu môn hình móng ngựa bằng chụp cộng hưởng từ và phẫu thuật tại bệnh viên Việt Đưức giai đoạn 2016-2019. Nghiên cứu mô tả có đối chứng. Kết quả: Qua nghiên cứu 56 bệnh nhân có 50 nam và 06 nữ. Chụp cộng hưởng từ phát hiện lố trong là 62.5\% với độ nhạy là $100 \%$ và độ đặc hiệu là $100 \%$. Tỷ lệ phù hợp với phẩu thuật trong phân loại đường rò chính là $93.3 \%$. Tỷ lệ phù hợp chụp cộng hưởng từ trực tràng xác định vị trí lỗ trong so với phẫu thuật là $100 \%$. Kết luận: Chụp cộng hưởng từ hậu môn trực tràng đã trở thành tiểu chuẩn vàng trong chẩn đoán rò hậu môn, đăc biệt là rò hậu môn hình móng ngựa trước phẫu thuật (phân loại đường rò chính, xác định vị trí lố trong và các tổn thương lan rộng) với độ chính xác cao.

Tư khóa: rò hậu môn hình móng ngựa, chụp cộng hưởng từ hậu môn trực tràng, phân loại đường rò.

\section{SUMMARY \\ RESEARCH ON THE ROLE OF MAGNETIC RESONANCE IN DIAGNOSIS AND SURGERY OF HORSESHOE SHAPED ANAL FISTULA AT VIET DUC HOSPITAL}

Objectives. Determine the relevance between magnetic resonance images and surgery in evaluating the inner hole and the horseshoe - shaped anal fistula. Subjects and Methods. Patients who are diagnosed with horseshoe - shaped anal fistula by taking magnetic resonance and sugery at Viet Duc Hospital from 2016 to 2019. This was a description study with control operation. Results. Among 56

\footnotetext{
${ }^{1}$ Bệnh viện Giao thông Vận tải TW,

²Bệnh viện Hữu Nghị Việt Đức

Chiu trách nhiệm chính: Bùi Sỹ Tuấn Anh

Email: DrTuanAnhbvgt@gmail.com

Ngày nhận bài: 20.10.2020

Ngày phản biện khoa học: 23.11.2020

Ngày duyệt bài: 8.12.2020
}

patients including 50 males and 06 females, 62.5 percent of them are detected inner hole by taking anal magnetic resonance with the sensitivity of $100 \%$ and the specificity of $100 \%$. The matching rate with surgery on classigyingfistula way is $93.3 \%$. There is a high precision in taking anal magnetic resonance image to locate the inner hole, with the matching rate of $100 \%$. Conclusions. Taking anal magnetic resonance has become the gold standard in anal fistula diagnosis, especially in horseshoe - shaped anal fistula before the surgery (classifying the main fistula tracts, locating the inner hole and defining the widespread injuries).

Keywords. Horseshoe - shaped anal fistula, Anorectal magnetic resonance image, classification of anal fistula.

\section{I. ĐĂTT VẤN ĐỀ}

Rò hậu môn hình móng ngựa là ổ áp xe lan tỏa từ một bên hố ngồi trực tràng sang hố ngồi trực tràng bên đối diện theo rễ nhánh của dải cơ dọc dài phức hợp ôm quanh thành hậu môn trực tràng tạo thành hình móng ngựa. phương pháp điều trị được áp dụng và đạt kểt quả cao nhất là phẫu thuật.

Chẩn đoán rò hâuu môn hình móng ngưa dựa vào: lâm sàng, các phương pháp chẩn đoán hình ảnh Xquang có bơm thuốc, siêu âm nội soi, chụp cộng hưởng từ...

Đã có nhiều nghiên cứu trên thế giới và Việt Nam về chẩn đoán rò hậu môn hình móng ngựa, tuy nhiên chưa có nhiều nghiên cứu về vai trò của cộng hưởng từ trong chẩn đoán rò hậu môn hình móng ngựa. Chính vì vậy chúng tôi tiến hành nghiên cứu vai trò của cộng hương từ trong chẩn đoán và phẫu thuật rò hậu môn hình móng ngựa.

\section{II. ĐốI TƯỢNG VÀ PHƯƠ'NG PHÁP NGHIÊN CỨU}

1. Đối tượng nghiên cứu: Những bệnh nhân được chẩn đoán rò hậu môn hình móng ngựa bằng cộng hưởng từ và phẫu thuật tại bệnh viện Việt Đức giai đoạn 2016 - 2019: 
2. Phương pháp nghiên cứu: Nghiên cứu mô tả có đối chứng

3. Các chỉ tiêu nghiên cứu: Ghi nhận tất cả các giá trị chụp cộng hưởng từ hậu môn trực tràng rò hậu môn hình móng ngựa phát hiện như:

$>$ Vị trí lỗ trong.

> Số lượng lỗ trong.

> Vị trí đường rò xuyên qua hệ thống cơ thắt. Các nhánh phụ ngóc ngách, phân loại đường rò với hệ thống cơ thắt, từ đó tìm sự phù hợp độ nhạy và độ đặc hiệu giữa chụp cộng hưởng từ và phẫu thuật.

\section{KẾT QUẢ NGHIÊN CỨU}

Đặc điểm chung. Qua nghiên cứu 56 bệnh nhân rò hậu môn hình móng ngựa cho thấy:

- Tuổi trung bình của bệnh nhân là 38,3 \pm 11,3; Tỉ lệ nam/nữ là 8,3/1.

- Xác định lố rò ngoài cho thấy 29 bệnh nhân có lỗ ngoài, chiếm tỷ lệ $51,79 \%$. Khoảng cách trung bình lỗ ngoài đến rìa hậu môn là $2,6 \pm 0,9$ (1-4), Iỗ ngoài cách rìa hậu môn khoảng cách 3 $-5 \mathrm{~cm}$, có 16 bệnh nhân $(55,2 \%)$ lỗ ngoài cách rìa hậu môn $>5 \mathrm{~cm}$ không có.

- Vị trí lỗ ngoài và lỗ trong so với định luật Goodsall theo kết quả nghiên cứu cho thấy định luật Goodsall đúng với tỷ lệ cao.

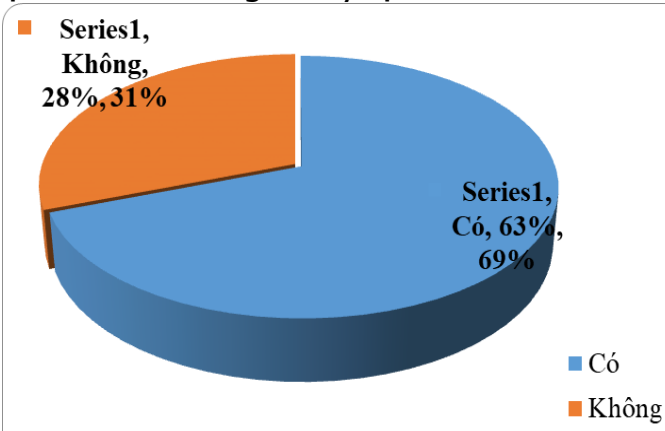

Biểu đồ 3.1 Tỷ lệ phát hiện tìm thây lỗ trong qua $\mathrm{CHT}(n=56)$

Nhận xét: Tỷ lế có hình ảnh tìm thây lỗ trong trên cộng hưởng từ là 62,5\% (35/56 Bệnh nhân).

Bảng 3.1: Chẩn đoán vị trí tìm thây lỗ trong theo $\mathrm{CHT}$

\begin{tabular}{|c|c|c|}
\hline $\begin{array}{c}\text { Vị trí lố trong trên } \\
\text { CHT }\end{array}$ & $\begin{array}{c}\text { Số lượng } \\
\text { (n) }\end{array}$ & $\begin{array}{c}\text { Tỷ lệ } \\
(\mathbf{\%})\end{array}$ \\
\hline $1 \mathrm{~h}$ & 2 & 5,7 \\
\hline $10 \mathrm{~h}$ & 0 & 2,8 \\
\hline $12 \mathrm{~h}$ & 0 & 2,8 \\
\hline $2 \mathrm{~h}$ & 2 & 5,7 \\
\hline $3 \mathrm{~h}$ & 0 & 8,6 \\
\hline $4 \mathrm{~h}$ & 0 & 2,8 \\
\hline
\end{tabular}

\begin{tabular}{|c|c|c|}
\hline $5 \mathrm{~h}$ & 4 & 11,5 \\
\hline $6 \mathrm{~h}$ & 21 & $60 \%$ \\
\hline $7 \mathrm{~h}$ & 3 & 8,6 \\
\hline $9 \mathrm{~h}$ & 1 & 2,8 \\
\hline $8 \mathrm{~h}$ & 1 & 2,8 \\
\hline $11 \mathrm{~h}$ & 1 & 2,8 \\
\hline Chung & $\mathbf{3 5}$ & $\mathbf{1 0 0}$ \\
\hline
\end{tabular}

Nhân xét: Lố trong tìm thấy gặp chủ yếu ở vị trí $6 \mathrm{~h}$, chiếm tỷ lệ $60 \%$.

Bảng 3.2: Tỷ lệ phù hợp vị trí tim thây lỗ trong giứa CHT và phẫu thuật

\begin{tabular}{|c|c|c|}
\hline $\begin{array}{c}\text { Tìm thấy lố trong } \\
\text { trên phấu thuật }\end{array}$ & $\begin{array}{c}\text { Số lượng } \\
\text { (n) }\end{array}$ & $\begin{array}{c}\text { Tỷ lệ } \\
(\mathbf{\%})\end{array}$ \\
\hline Có & 35 & 62,5 \\
\hline Không & 21 & 37,5 \\
\hline Tống số & $\mathbf{5 6}$ & $\mathbf{1 0 0}$ \\
\hline
\end{tabular}

Nhận xét: Trong phầu thuật, tỷ lệ phát hiện lỗ trong là $62,5 \%$ (35/56 Bệnh nhân). tỷ lệ phát hiện trong phấu thuật phù hợp với phát hiện trên CHT là $100 \%$.

Bảng 3.3: Phân bố vị trí lỗ trong trong phẫu thuật

\begin{tabular}{|c|c|c|}
\hline $\begin{array}{c}\text { Vị trí lồ̂ trong trên } \\
\text { phẫu thuật }\end{array}$ & $\begin{array}{c}\text { Số lượng } \\
\text { (n) }\end{array}$ & $\begin{array}{c}\text { Tỷ lệ } \\
(\mathbf{\%})\end{array}$ \\
\hline $1 \mathrm{~h}$ & 2 & 5,7 \\
\hline $2 \mathrm{~h}$ & 2 & 5,7 \\
\hline $5-7 \mathrm{~h}$ & 28 & 80 \\
\hline $11 \mathrm{~h}$ & 1 & 2,8 \\
\hline $8 \mathrm{~h}$ & 1 & 2,8 \\
\hline $9 \mathrm{~h}$ & 1 & 2,8 \\
\hline Tổng số & $\mathbf{3 5}$ & $\mathbf{1 0 0}$ \\
\hline
\end{tabular}

Nhân xét: Tìm thấy vị trí lỗ trong trong phẫu thuật chủ yếu là hướng 6 h, chiếm tỷ lệ $78,2 \%$.

Bảng 3.4: Độ nhạy và độ đặc hiệu xác định tim thây lố trong qua chụp cộng hưởng từ

\begin{tabular}{|c|c|c|c|c|}
\hline \multirow{2}{*}{\multicolumn{2}{|c|}{$\begin{array}{l}\text { Phương pháp } \\
\text { chẩn đoán }\end{array}$}} & \multicolumn{2}{|c|}{$\begin{array}{l}\text { Phẫu thuật phát } \\
\text { hiện lố trong }\end{array}$} & \multirow{3}{*}{$\begin{array}{c}\begin{array}{c}\text { Tổng } \\
\text { số }\end{array} \\
35 \\
\end{array}$} \\
\hline & & Có & Không & \\
\hline \multirow{2}{*}{$\begin{array}{l}\text { CHT phát } \\
\text { hiện } \\
\text { lỗ trong }\end{array}$} & Có & 35 & 0 & \\
\hline & Không & 0 & 21 & 21 \\
\hline \multicolumn{2}{|c|}{ Tổng số } & 35 & 21 & 56 \\
\hline \multicolumn{5}{|c|}{$\begin{array}{c}\text { Độ nhay: } 35 /(35+0)=100 \% \\
\text { Đọ đặc hiệu: } 21 /(21+0)=100 \% \\
\text { Giá trị dự đoán dương tính }(\mathrm{PV})= \\
35 /(35+0)=100 \% \\
\text { Giá trị dự đoán âm tính }(\mathrm{PV}-)= \\
21 /(21+0)=100 \%\end{array}$} \\
\hline
\end{tabular}

Nhận xét: Phương pháp chẩn đoán bằng hình ảnh cộng hưởng từ cho độ nhạy và độ đặc hiệu là $100 \%$ đối với việc phát hiện lỗ trong. 
3.5: Phân loại rò hậu môn phát hiện qua chụp cộng hưởng từ:

\begin{tabular}{|c|c|c|}
\hline Phân loại đường rò & $\begin{array}{c}\text { Số lượng } \\
\text { (n) }\end{array}$ & $\begin{array}{c}\text { Tỷ lệ } \\
(\mathbf{\%})\end{array}$ \\
\hline Rò xuyên cơ thắt trung gian & 28 & 50,0 \\
\hline Rò xuyên cơ thắt cao & 11 & 19,6 \\
\hline Rò trên cơ thắt & 11 & 19,6 \\
\hline Rò ngoài cơ thắt & 6 & 10,8 \\
\hline Tổng số & $\mathbf{5 6}$ & $\mathbf{1 0 0}$ \\
\hline
\end{tabular}

Nhận xét: Trên hình ảnh cộng hưởng từ, cho thấy có 28 trường hợp rò xuyên cơ thắt trung gian, chiếm tỷ lệ $50,0 \%$; 11 bệnh nhân rò xuyên cơ thắt cao $(19,6 \%) ; 11$ bênh nhân rò trên cơ thắt $(19,6 \%)$ và 06 bệnh nhân rò ngoài cơ thắt $(10,8 \%)$.

3.6: tỷ lê phù hợ vị trí đường rò qua chụp cộng hưởng từ và phẫu thuật:

\begin{tabular}{|c|c|c|c|}
\hline Thể rò hậu môn & CHT & $\begin{array}{c}\text { Phấu } \\
\text { thuật }\end{array}$ & $\begin{array}{c}\text { Tỷ lệ phù } \\
\text { hợp (\%) }\end{array}$ \\
\hline $\begin{array}{c}\text { Rò xuyên cơ thắt } \\
\text { trung gian }\end{array}$ & 28 & 30 & $93,3 \%$ \\
\hline Rò xuyên cơ thắt cao & 11 & 12 & $91,7 \%$ \\
\hline Rò trên cơ thắt & 11 & 13 & $84,6 \%$ \\
\hline Rò ngoài cơ thắt & 6 & 1 & $16,7 \%$ \\
\hline
\end{tabular}

Nhận xét: Tỷ lệ phù hợp của phương pháp chẩn đoán hình ảnh bằng cộng hưởng từ so với kết quả trong phẫu thuật cao nhất ở thể rò xuyên cơ thắt trung gian chiếm 93,3\%.

Tỷ lệ phù hợp của phương pháp chẩn đoán hình ảnh bằng cộng hưởng từ với thể rò xuyên cơ thắt cao so với phấu thuật là $91,7 \%$. Tỷ lệ này ở thể rò trên cơ thắt và rò ngoài cơ thắt lần lượt là $84,6 \%$ và $16,7 \%$.

\section{BÀN LUẬN}

Chụp cộng hưởng từ là phương pháp chẩn đoán không xâm hại và có giá trị rất cao trong chẩn đoán bệnh lý vùng hậu môn trực tràng nói chung và rò hậu môn hình móng ngựa nói riêng. Hiện nay các nhà hậu môn học đều nhận định và công nhận chụp cộng hưởng từ là tiêu chuẩn vàng trong chẩn đoán bệnh lý rò hậu môn đặc biệt là thể rò hậu môn hình móng ngựa.

Chúng tôi nghiên cứu 56 bệnh nhân rò hậu môn hình móng ngựa được chẩn đoán bằng chụp cộng hưởng từ tại bệnh viện Việt Đức kết quả cho thây: chụp cộng hưởng từ mô tả lỗ trong với 35/56 bệnh nhân ( chiếm $62,5 \%$ ). Tỷ lệ phù hợp của MRI so với phẫu thuật là $100 \%$ trường hợp, độ nhạy là $100 \%$, độ đặc hiệu là $100 \%$. Nghiên cứu của chúng tôi tương tự như một số tác giả khác trong và ngoài nước như: Kulvinder Sigh và cộng sự (2014) chụp cộng hưởng từ cho kết quả độ nhạy 87,5\%, độ đặc hiệu 92,24\%; Lê Thị Diễm là 87\%; Buchanan là $97 \%$, Nguyễn Ngọc Anh độ nhạy 100\%.

Uuu điểm của chụp cộng hưởng từ trong chẩn đoán rò hậu môn hình móng ngựa: chụp cộng hưởng từ được xem là kỹ thuật có giá trị cao trong chẩn đoán, nhờ cho ra hình ảnh có độ phân giải cao và trường khảo sát rộng, giúp phân loại đường rò chính cũng như xác định vị trí lỗ trong và các tổn thương lan rộng với độ chính xác cao, nhất là những tổn thương nằm trên cơ nâng hậu môn. Từ đó giúp phẫu thuật viên lên kế hoạch điều trị triệt để đường rò cũng như các phân nhánh hoặc ổ viêm lan rộng xung quanh, giảm tỉ lệ tái phát sau mổ đêen $75 \%$ trường hợp RHM hình móng ngựa.

\section{KẾT LUÂ̂N}

Chụp MRI đã trở thành phương pháp chẩn đoán rò hậu môn hình móng ngựa trước phẫu thuật với độ chính xác cao và trên tiêu chuẩn vàng trong chẩn đoán. Tỷ lệ phù hợp so với phẫu thuật trong phân loại đường rò là $100 \%$. Tỷ lệ xác định vị trí lỗ trong qua MRI $62,5 \%$, với độ nhạy và độ đặc hiệu xác định lố trong qua chụp cộng hưởng từ là $100 \%$.

\section{TÀI LIÊU THAM KHẢO}

1. Buchanan, G.N., et al., Efficacy of fibrin sealant in the management of complex anal fistula: a prospective trial. Dis Colon Rectum, 2003. 46(9): p. 1167-74.

2. Lê Thị Diễm, et al., Bước đâu khảo sát giá trị hình ảnh cộng hưởng từ của rò hậu môn.Tạpchí Y học TP Hồ Chí Minh, 2010. 14(1): p. 87-91.

3. Vương Ngọc Anh, Đặc điểm và vai trò của cộng hưởng từ trong chẩn đoán rò hậu môn. 2015, Trường Đại học Y Hà Nội: Hà Nội.

4. Phạm Thị Thanh Huyền, Kết quả điêu trị phẫu thuật bệnh rò hậu môn có ứng dụng cộng hưởng từ trước mổ tại bệnh viện hữu nghị Việt Đức. 2019, Trường Đại học Y Hà Nội

5. Singh, K., et al., Mágnetic resonance imaging (MRI) evaluation of perianal fistulae with surgical correlation. J Clin Diagn Res, 2014. 8(6): p. Rc01-4.

6. Torkzad, M.R. and U. Karlbom, MRI for assessment of anal fistula. Insights Imaging, 2010. 1(2): p. 62-71.

7. Konan, A., M.R. Onur, and M.N. Özmen, The contribution of preoperative MRI to the surgical management of anal fistulas. Diagn Interv Radiol, 2018. 24(6): p. 321-327.

8. Mahjoubi, B., et al., Diagnostic accuracy of body coil MRI in describing the characteristics of perianal fistulas. Colorectal Dis, 2006. 8(3): p. 202-7.

9. Barker, P.G., et al., Magnetic resonance imaging of fistula-in-ano: technique, interpretation and accuracy. Clin Radiol, 1994. 49(1): p. 7-13. 